\title{
Macrophage Activation Syndrome Discovered During Pregnancy: Case Report
}

\author{
Meriem Serraj Andaloussi ${ }^{1 *}$,Hayat Midyani ${ }^{1}$,Chadia Khalloufi ${ }^{1}$,Amine Lamrissi ${ }^{1}$, Karima Fichtali ${ }^{1}$, Said Bouhya ${ }^{1}$,Salah Hayar 2 , Ihsane \\ Moussaid $^{2}$, Smail El Youssoufi ${ }^{2}$, Said Salmi ${ }^{2}$ \\ ${ }^{1}$ Gynecology-Obstetrics Department EL HAROUCHI, University Hospital Center IBN ROCHD, CASABLANCA, MOROCCO \\ ${ }^{2}$ Maternity Reanimation Service, Gynecology-Obstetrics Department EL HAROUCHI ,University Hospital Center IBN ROCHD ,CASABLANCA, \\ MOROCCO \\ ${ }^{*}$ Corresponding Author: Meriem SERRAJ ANDALOUSSI, Gynecology-Obstetrics Department EL HAROUCHI, University Hospital Center \\ IBN ROCHD, CASABLANCA, MOROCCO
}

Received date: June 01, 2021; Accepted date: June 05, 2021; Published date: June 24, 2021

Citation: Meriem S. Andaloussi , Midyani H., Khalloufi C., Lamrissi A., Fichtali K., Bouhya S. , Hayar S., Moussaid I, Smaïl E. Youssoufi, Salmi S. (2021) Macrophage Activation Syndrome Discovered During Pregnancy: Case Report. J.Obstetrics Gynecology and Reproductive Sciences. 5(5): DOI: $10.31579 / 2578-8965 / 081$

Copyright: (02021, Meriem Serraj Andaloussi, This is an open access article distributed under the Creative Commons Attribution License, which permits unrestricted use, distribution, and reproduction in any medium, provided the original work is properly cited.

\begin{abstract}
:
Macrophage activation syndrome (MAS) or Haemophagocytic syndrome (HPS) results from an inappropriate stimulation of macrophages in bone marrow and lymphoid organs, leading to haemophagocytosis and hypercytokinemia. HPS may be primitive, essentially in pediatric population, or secondary to malignancy, infection or autoimmune disease. This disease is rare and prognosis is poor.

The diagnosis of hemophagocytic syndrome remains a challenge especially during pregnancy. We report a case collected at the Elharouchimaternity service, taken in charge jointly with its intensive care unit, of a 26-year-old patient with no pathological history leading to an unsuccessful pregnancy presumed at 5 months in whom the MAS syndrome was retained due to pancytopenia., hyperferitinemia, hypertriglyceridemia with the presence of a few hemophagocytes in the myelogram with a good evolution under bolus of solumedrol and symptomatic treatment. We discuss through this case the diagnostic difficulties, the obstetric complications as well as the options therapeutic.
\end{abstract}

Keywords: diagnosi, hemophagocytic syndrome, pregnancy

\section{Introduction:}

Macrophagic activation syndrome (MAS) is characterized by inappropriate stimulation of cells of the monocytomacrophage system in tissues, especially in the bone marrow and the lymphoid system responsible for hemophagocytosis and hypercytokinemia [1]. This syndrome can be primary, mainly in children, or secondary to a neoplastic, infectious or autoimmune disease [2]. It is a rare condition with an often unfavorable prognosis [3]. Only a fewcases during pregnancy are described in the literature [1]. The often unspecific picture is the cause of diagnostic and therapeutic delay and the occurrence of complications. It is the entanglement with the suggestive biological signs that points to this diagnosis. We note, in this pathology, bicytopenia or pancytopenia, an increase in $\mathrm{LDH}$, hypertriglyceridemia, hyperferritinemia and hypercytokinemia[2].It is often bone marrow cytology that can confirm the diagnosis in the presence of hemophagocytosis, which is a necessary condition, but not sufficient to confirm the diagnosis [3]. Therapeutic care is not consensual, but urgent. Its occurrence during pregnancy is rare. We report the case of a patient in whom MAS occurred during a first pregnancy.

\section{Case History:}

A 26 -year-old patient, primigravida primiparous, with no particular pathological history, admitted for an afebrile consciousness disorder in an unsuccessful pregnancy presumed at 5 months. The clinical examination shows a Glasgow coma scale of $2 / 15$, normotensive, a respiratory rate at 20cycles / min, a heart rate at 90 beats / min, afebrile, arterial oxygen saturation $(\mathrm{SaO} 2)$ at $97 \%$ at free air and negative urine test strips (BU). Obstetrically, the patient was outside of labor with, on obstetric ultrasound, an active monofetal pregnancy (GMFE), biometrics of 20 weeks of amenorrhea and sufficient amniotic fluid (LA). Due to her neurogicaldeterioration, she was transferred as soon as she was admitted to an intensive care unit. On day 2 of her hospitalization, she presented with a fever of $39 \mathrm{C}^{\circ}$ with respiratory distress, and an infectious assessment was carried out with a blood culture, a negative CRP and a negative cytobacteriological examination of the urine (ECBU), an abdominal ultrasound. and a normal chest x-ray; Then she underwent a brain MRI which revealed moderate triventricular dilation without signs of ependymal resorption. Laboratory workup showed pancytopenia made up of aregenerative normochromic normocytic anemia at $6.7 \mathrm{~g} / \mathrm{dl}, \mathrm{GB}=$ $3900 / \mathrm{mm} 3$, thrombocytopenia with platelets at $53000 / \mathrm{mm} 3$, urea / creatinine $=0.28 / 7.2$, ASAT $/$ ALAT $=104 / 33$, prothrombin level 65\%, fibrinogen $1.4 \mathrm{~g} / 1$, negative serologies (syphilitic, HVB, HCV, HIV). 
Because of the pancytopenia a myelogram was indicated objectifying a marrow of normal richness with the presence of some hemophagocytes. It was completed by an immunological assessment made of antinuclear antibodies (ANA) and native anti DNA antibodies returned negative; C3 $=1.17 \mathrm{~g} / 1, \mathrm{C} 4=0.23 \mathrm{~g} / 1$. As well as normal troponins at 2.9 , total cholesterol $=1.6 \mathrm{~g} / 1$, HDL-cholesterol $=0.33 \mathrm{~g} / 1$, LDL-cholesterol $=$ $1.93 \mathrm{~g} / 1$, Triglycerides high at $5.4 \mathrm{~g} /$ let hyperferritinemia at $800 \mathrm{ng} / \mathrm{ml}$. of her hospitalization, she presented elevated blood pressure figures at $09 / 15 \mathrm{cmHg}$ without clinical or biological signs of seriousness, it was supplemented by a 24 hour proteinuria which returned positive at $0.9 \mathrm{~g} /$ $24 \mathrm{~h}$. MAS was retained for lapancytopenia, hypertriglyceridemia, hyperferritinemia and hemophagocytosis objectified in the myelogram, then the patient was placed on a bolus of solumedrol and symptomatic treatment. The evolution was good, with a gradual improvement in her condition and was declared discharged on day 20. Fetal surveillance did not demonstrate IUGR. She delivered vaginal term without complications with a newborn with an Apgar 9/10.

\section{Discussion:}

MAS is a rare condition, especially during pregnancy. Its prevalence in children and adults according to Imashuku et al. is of the order of 51.7 cases per year [4] while its incidence varies between 0.9 and 3.6 cases per $1,000,000$ individuals depending on the series, but probably underdiagnosed [5]. Given the variable immunological disturbances during pregnancy, this becomes a favorable context for triggering MAS, especially in the presence of additional risk factors such as systemic disease or infection [6]. In the literature, there have been only a few cases of MAS reported during pregnancy with sometimes fatal fetal and maternal outcomes $[1,3,7,8]$. The average age of onset during pregnancy is 31 years and the diagnosis is made in the second trimester (approximately 22 weeks) [7-14].As is the case with our patient where the diagnosis was made around the 5th month of pregnancy.

The diagnosis of hemophagocytic syndrome is difficult [5]. given its rare but serious features often requiring intensive care. the clinical picture associates an almost constant fever with a deterioration of the general condition, a hepato-splenomegaly in almost $50 \%$ of cases and often a tumor syndrome of the lymphoid type[13].Cutaneous, neurological, digestive signs or even a syndrome of multiple visceral failure may be present, but are more inconsistent [1]. Indeed, even if certain clinical and biological signs are recurrent in this pathology, they are nonetheless few. specific. The diagnosis must be made in the face of a combination of clinical and laboratory signs and the unusual course of symptoms, namely hyperthermia that persists for more than seven days despite antibiotic therapy [1]. Thus, in the face of a strong clinical and laboratory suspicion of MAS, the myelogram should be repeated even if it was considered negative. In fact, hemophagocytosis varies over time and according to the phases of MAS. In our case, a single myelogram was sufficient which showed the presence of hemophagocytes, which guided us more towards the diagnosis in association with the clinicobiological picture and the favorable evolution under treatment with corticosteroids. the bone marrow is double: it makes it possible, on the one hand, to look for a hemopathy, on the other hand it can highlight signs of hemophagocytosis, in the context of a macrophage activation syndrome (MAS)[911].Emophagocytosis, although highly suggestive, is not pathognomonic for MAS and further diagnostic criteria are needed [5]. Fardet et al. developed a diagnostic score for adult HPS. It is made up of several components: autoimmune disease, peak temperature, hepatomegaly, splenomegaly, hemoglobin level, platelet and leukocyte count, hyperferritinemia, hypertriglyceridemia, fibrinogen and transaminase level, hemophagocytosis found in the bone marrow. This score is a diagnostic aid for the obstetrician gynecologist faced with a rare but serious pathology that is often underdiagnosed [15]. Based on this score, there was an $85.3 \%$ probability that our patient had MAS. The etiological investigation plays an important role in the diagnostic process. A neoplasia should be looked for, as well as a bacterial, fungal, parasitic or viral infection. Viral infections with viruses of the herpes group (CMV, EBV, HSV, VZV, HIV, HHV-6 and HHV-8) are responsible for more than half of post-infectious MAS [5]. Table 1 from a point of view obstetric, hypercytokinemia induced during MAS is believed to be a risk factor for vascular pathology such as intrauterine growth retardation, preeclampsia or HELLP syndrome. Thus, in the described cases of MAS during pregnancy, a case of eclampsia with ventricular haemorrhage [4], a case of pre-eclampsia [10], a case of HELLP syndrome [2] and two premature newborns has been reported. with intrauterine growth retardation $[2,10]$. While HELLP syndrome is a possible complication of MAS during pregnancy, it also remains the main differential diagnosis described in the literature. In fact, the two syndromes have bicytopenia and hepatic cytolysis in common. The mechanism of bicytopenia (anemia and thrombocytopenia) is peripheral for HELLP syndrome. In MAS, aregenerative normochromic normocytic anemia is of central origin through hemophagocytosis, sometimes associated with peripheral hemolysis. The same mechanism of central phagocytosis is found for thrombocytopenia, which can also be peripheral by DIC [5-8].It is the presence of hyperthermia, the absence of arterial hypertension and proteinuria and the non-regression of symptoms after childbirth that should also point to the diagnosis of MAS [2]. For some authors, pregnancy itself. even is considered to be at the origin of this syndrome [9]. Our patient developed on day 15 of her hospitalization a preeclampsia objectified by arterial blood pressure figures raised to $15 / 09 \mathrm{mmHg}$ with a proteinuria of $24 \mathrm{~h}$ to $0.9 \mathrm{~g} / 24 \mathrm{~h}$ without neurological signs of severity neither cytolysis or hemolysis, which could be a complication of MAS. In the face of a negative etiological investigation, pregnancy seems to be responsible for MAS. Therapeutic care is not consensual, but urgent. It includes first the treatment of the causative disease and the control of the macrophage reaction, then the management of fluid and electrolyte disturbances[12].Iterative transfusions are sometimes necessary to correct pancytopenia [16]. Immunoglobulins and corticosteroids are widely used. Yamaguchi et al. [12] used cyclosporin A after the onset of corticosteroid resistance. Prahalad et alused antithrombin after failure of corticosteroids and immunoglobulins. Antithrombin may have an effect in preventing deep vein thrombosis. Future treatments may be anti-TNFalpha antibodies to inhibit macrophage activation [17].

In our case, the patient required iterative transfusions of red blood cells and platelets while the corticosteroid boluses were sufficient to control the disease, and normalization of the laboratory parameters. The spontaneously favorable outcome remains rare. Mortality in the first weeks of the disease is linked to multiple organ dysfunctions while, later, it is associated with the toxicity of the treatments and the possible appearance of infections. opportunistic [18] in our patient, the absence of an underlying immunosuppression, comorbidities ormajor history probably favored rapid remission. 


\begin{tabular}{|c|c|c|}
\hline INFE CTIONS (41\%) & $\begin{array}{l}\text { Virals } \\
\text { BACTERIALS } \\
\text { PARASITAIRE } \\
\text { S }\end{array}$ & $\begin{array}{l}\text { EBV+++, CMV, HSV, VZV, PARBO } \\
\text { B } 19, \text { VHA,VHB,VHC,ADENOVIRUS,VI } \\
\text { H } \\
\text { MYCOBACTERIUM TUBERCULOSIS, } \\
\text { LEGIONELLA } \\
\text { RCKETTSIA,BRUCELLA, } \\
\text { MYCOPLA SMA, PYOGENES } \\
\text { LEISHMANIA, TOXOPLASMA }\end{array}$ \\
\hline $\begin{array}{l}\text { ONCOHEMAT OLOGI } \\
\text { C DISE ASE }(38 \%)\end{array}$ & FONGTIQUE & $\begin{array}{l}\text { HISTOPALSMOSE, CANDIDA } \\
\text { lymphoma, leukemia }\end{array}$ \\
\hline $\begin{array}{l}\text { AUT OIM MUNE } \\
\text { DISE ASE S }(10 \%)\end{array}$ & & $\begin{array}{l}\text { Lupus, still's disease , rheumatoid arthritis, } \\
\text { MICI,vasculitis }\end{array}$ \\
\hline $\begin{array}{l}\text { OTHER }(7 \%) \\
\text { IDIOPAT HIC }(4 \%)\end{array}$ & & transplant,pregnancy, \\
\hline
\end{tabular}

Table 1: Main causes of secondary macrophage activation syndrome (MAS) (after [1]

\section{Conclusion}

The pathophysiology of MAS is not yet fully understood. The dysimmunity field seems to be responsible; cytokine hypersecretion is thought to be at the origin of this syndrome. Immune modifications and the activation of cytokines induced by pregnancy could create a favorable ground for the development of this syndrome in genetically predisposed women. The prognosis of MAS is poor and depends on the etiology, mortality is between 30 and 50\% depending on the series. This syndrome exposes the risk of maternal mortality from multiple organ failure. Concerning the fetus, the activation of cytokines during MAS is thought to be responsible for intrauterine growth retardation, pre-eclampsia or HELLP syndrome.

\section{Declaration of interests}

The authors declare that they have no conflicts of interest in relation to this article.

\section{References}

1. Hannebicque-Montaigne, K., Launay, D., Coulon, C., Deruelle, P., \& Langlois, S. (2012). Haemophagocytic syndrome in pregnancy: a case report. In Annales francaises d'anesthesie et de reanimation (31(3):239-242).

2. Gonzalez, F., Vincent, F., \& Cohen, Y. (2009). Infectionrelatedhemophagocytic syndrome: etiologies and management. Réanimation, 18(4), 284-290.

3. Chmait, R. H., Meimin, D. L., Koo, C. H., \&Huffaker, J. (2000). Hemophagocytic syndrome in pregnancy. Obstetrics \& Gynecology, 95(6), 1022-1024.

4. Imashuku, S., Hibi, S., Fujiwara, F., Ikushima, S., \&Todo, S. (1994). Haemophagocyticlymphohistiocytosis, interferongamma-naemia and Epstein-Barr virus involvement. British journal of haematology, 88(3), 656-658.

5. Lu, H., Simonetta, F., Samii, K., \& Juillet, C. (2017). Syndrome d'activation macrophagique. In Forum Médical Suisse. (17(282) : 604-610).EH Media.

6. Rivière, S., Galicier, L., Coppo, P., Marzac, C., Aumont, C., Lambotte, O., \&Fardet, L. (2014). Reactive hemophagocytic syndrome in adults: a retrospective analysis of 162 patients. The American journal of medicine, 127(11), 11181125 .

7. Teng, C. L., Hwang, G. Y., Lee, B. J., Wang, R. C., \& Chou, M. M. (2009). Pregnancy-induced hemophagocytic lymphohistiocytosis combined with autoimmune hemolytic anemia. Journal of the Chinese Medical Association, 72(3), 156-159.

8. Mayama, M., Yoshihara, M., Kokabu, T., \&Oguchi, H. (2014). Hemophagocytic lymphohistiocytosis associated with a parvovirus B19 infection during pregnancy. Obstetrics \& Gynecology, 124(2), 438-441.

9. Pérard, L., Costedoat-Chalumeau, N., Limal, N., Hot, A., Cohen, J., Vauthier-Brouzes, D., ... \&Piette, J. C. (2007). Hemophagocytic syndrome in a pregnant patient with systemic lupus erythematosus, complicated with preeclampsia and cerebral hemorrhage. Annals of hematology, 86(7), 541-544.

10. Nakabayashi, M., Adachi, T., Izuchi, S., \&Sugisaki, A. (1999, October). Association of hypercytokinemia in the development of severe preeclampsia in a case of hemophagocytic syndrome. In Seminars in thrombosis and hemostasis (25(5): 467-471). Copyright $\odot 1999$ by Thieme Medical Publishers, Inc..

11. Rousselin, A., Alavi, Z., Le Moigne, E., Renard, S., Tremouilhac, C., Delluc, A., \&Merviel, P. (2017). Hemophagocytic syndrome in pregnancy: case report, diagnosis, treatment, and prognosis. Clinical case reports, 5(11), 1756.

12. Ramasamy, K., Lim, Z. Y., Savvas, M., Salisbury, J. R., Dokal, I., Mufti, G. J., \&Pagliuca, A. (2006). Disseminated herpes virus (HSV-2) infection with rhabdomyolysis and hemophagocytic lymphohistiocytosis in a patient with bone marrow failure syndrome. Annals of hematology, 85(9), 629630.

13. Hanaoka, M., Tsukimori, K., Hojo, S., Abe, Y., Mutou, T., Muta, K., ... \& Nakano, H. (2007). B-cell lymphoma during pregnancy associated with hemophagocytic syndrome and placental involvement. Clinical Lymphoma and Myeloma, 7(7), 486-490.

14. Shukla, A., Kaur, A., \& Hira, H. S. (2013). Pregnancy induced haemophagocytic syndrome. The Journal of Obstetrics and Gynecology of India, 63(3), 203-205. 
15. Fardet, L., Galicier, L., Lambotte, O., Marzac, C., Aumont, C., Chahwan, D., Coppo, P., \&Hejblum, G. (2014). Development and validation of the HScore, a score for the diagnosis of reactive hemophagocytic syndrome. Arthritis\&rheumatology (Hoboken, N.J.), 66(9), 2613-2620.

16. Karras, A., \& Hermine, O. (2002). Syndrome d'activation macrophagique. La revue de médecine interne, 23(9), 768-778.
17. Prahalad, S. A. M. P. A. T. H., Bove, K. E., Dickens, D. A. V. I. D., Lovell, D. J., \&Grom, A. A. (2001). Etanercept in the treatment of macrophage activation syndrome. The Journal of rheumatology, 28(9), 2120-2124.

18. Ramos-Casals, M., Brito-Zerón, P., López-Guillermo, A., Khamashta, M. A., \& Bosch, X. (2014). Adult haemophagocytic syndrome. The Lancet, 383(9927), 15031516.
This work is licensed under Creative Commons Attribution 4.0 License

\section{To Submit Your Article Click Here: Submit Manuscript}

DOI: $10.31579 / 2578-8965 / 081$
Ready to submit your research? Choose Auctores and benefit from:

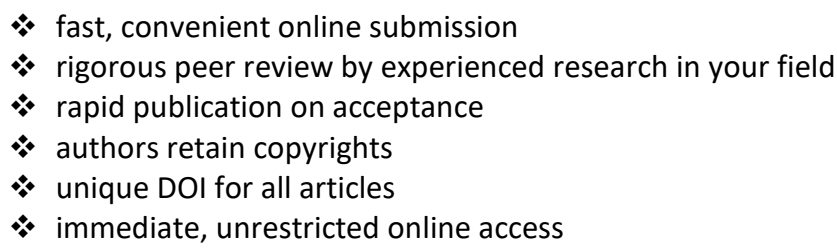

At Auctores, research is always in progress.

Learn more www.auctoresonline.org/journals/biomedical-research-andclinical-reviews- 